\begin{tabular}{|l|l|l|}
\hline \multicolumn{2}{|c|}{ PublisherInfo } \\
\hline \hline PublisherName & $:$ & BioMed Central \\
\hline \hline PublisherLocation & $:$ & London \\
\hline \hline PublisherImprintName & $:$ & BioMed Central \\
\hline \hline
\end{tabular}

\title{
Making enzymes from proteins
}

\begin{tabular}{|l|l|l||}
\hline \multicolumn{2}{|c|}{ ArticleInfo } \\
\hline \hline ArticleID & $:$ & 4971 \\
\hline \hline ArticleDOI & $:$ & $10.1186 /$ gb-spotlight-20040629-02 \\
\hline \hline ArticleCitationID & $:$ & spotlight-20040629-02 \\
\hline \hline ArticleSequenceNumber & $:$ & 34 \\
\hline \hline ArticleCategory & $:$ & Research news \\
\hline ArticleFirstPage & $:$ & 1 \\
\hline \hline ArticleLastPage & $:$ & 3 \\
\hline \hline & & RegistrationDate : 2004-6-29 \\
\hline ArticleHistory & $:$ & OnlineDate \\
\hline \hline ArticleCopyright & $:$ & BioMed Central Ltd2004-6-29 \\
\hline \hline ArticleGrants & $:$ & \\
\hline \hline ArticleContext & $:$ & 130595511 \\
\hline \hline
\end{tabular}


Using computational design, researchers have transformed a protein with no catalytic abilities into a highly active enzyme. Scientists said the experiment, reported in the June 25 Science, represents a valuable step in the quest to design enzymes from scratch (Science 2004, 304:1967-1971).

"In principle, the design tools are general and may be used to design many different enzymes at will. If this turns out to be true, then we can really start to design catalysts at will," Homme Hellinga at Duke University Medical Center in Durham, NC, senior author on the paper, told us.

Hellinga and his team began with ribose-binding protein (RBP), a molecule they had in prior computational biology experiments made into a high-affinity receptor for nonnatural ligands such as serotonin and trinitrotoluene. Their latest research transformed RBP into an enzyme highly active as a triose phosphate isomerase (TIM). TIM is active in glycolysis, catalyzing the interconversion between the ketose dihydroxyacetone phosphate (DHAP) and the aldose glyceraldehyde-3-phosphate (GAP).

"This is really the best demonstration to date that these algorithms can be useful for real practical problems and also for providing fundamental insight into how enzymes do what they do," said Bill DeGrado at the University of Pennsylvania School of Medicine in Philadelphia, who was not involved in the study.

TIM's catalytic abilities have their origins in the precise orientation of three critical amino acid residues - glutamate, histidine, and lysine - in its active site and in controlled movements of the protein chain during catalysis. To transform RBP into TIM, the researchers used algorithms to predict mutations that altered RBP's layer of residues so it could bind GAP and DHAP.

The authors then introduced catalytically active residues into this receptor design. First, they defined the most favorable geometrical orientations of key interactions contributing to catalysis-specifically, those of the three catalytically essential residues glutamate, histidine, and lysine with respect to the enediol intermediate. Next, the researchers used a combinatorial search algorithm to find positions for these residues that satisfy these geometrical constraints. Finally, they used their receptor design algorithm to optimize the potential active site.

Fourteen RBP variants were designed, produced, and assayed for TIM activity. Just like TIM, the RBP variants had a mechanism to close the active site after the substrate was bound, except they used a hinge-bending mechanism. The most active variant was much less thermostable than native RBP and was stabilized with computational design by adding mutations to the protein matrix, correcting interactions with the binding surfaces it surrounded.

The resulting RBP variant NovoTim1.2, which had additional surface amino acid substitutions remote from the active site, catalyzed the TIM reaction at a rate 100,000- to 1,000,000-fold more efficiently than uncatalyzed reactions. It also proved biologically active, supporting the growth of Escherichia coli under gluconeogenic conditions just as regular TIM would.

"In the long run, this work could help to establish natural as well as nonnatural reactions on natural as well as artificial protein scaffolds. This could help to make chemical transformations more environment 
friendly or to produce tailored pharmaceuticals," Reinhard Sterner at the University of Regensburg in Germany, who was not involved in the study, told us.

To further improve the catalytic activity, the authors turned to directed evolution. NovoTim1.2 was further mutagenized randomly by an error-prone polymerase chain reaction. Because TIM is absolutely necessary for gluconeogenic growth on glycerol, according to Hellinga, the researchers plated about 100,000 cells on glycerol to select for improved mutants, and four colonies survived.

"It remains to be demonstrated, but I think their approach has the potential for tremendous generality. There are many reactions one would like to catalyze that have no enzyme in nature, or the enzymes that are in nature are highly fragile. So far, the approaches that have been taken are random screening or directed evolution. What they're showing here is computation, when combined with these experimental methods, now may allow one to have new starting points for evolution of highly effective and highly novel catalysts," DeGrado said.

Although the variant's efficiency parameters were about three orders of magnitude below that of wildtype TIM, Sterner and Franz Schmid of the University of Bayreuth in Germany, in a perspective accompanying Hellinga's team's paper, wrote that "this reduced efficiency does not diminish the achievement, considering that native TIM is a kinetically perfect enzyme with a turnover that is limited only by the diffusion-determined rate at which substrate and enzyme encounter each other."

Researchers first tried to design enzymes de novo in the 1980s and came up with the first catalytic antibodies, known as abzymes. Recently, scientists at Caltech used computational design to transform the catalytically inert protein thioredoxin into an esterase. However, both abzymes and the designed thioredoxin are much less active than the RBP variants transformed into TIM, Sterner said.

\section{References}

1. Science, [http://www.sciencemag.org]

2. Homme W. Hellinga, [http://www.biochem.duke.edu/Hellinga/hellinga.html]

3. Triose Phosphate Isomerase, [http://www.bio.cmu.edu/Courses/03231/ProtStruc/1ypi.htm]

4. William F. DeGrado, [http://www.uphs.upenn.edu/biocbiop/faculty/pages/degrado.html]

5. Reinhard Sterner, [http://www.uni-koeln.de/math-nat-fak/biochemie/sterner/Home.htm]

6. Catalytic antibodies

7. Selective chemical catalysis by an antibody

8. Abzymes: Catalytic Antibodies, [http://www.whfreeman.com/immunology/CH05/catab.htm] 